\title{
Additional Surgical Resection After Endoscopic Resection for Patients With High-risk T1 Colorectal Cancer
}

\author{
KENTA IGUCHI $^{1}$, HIROYUKI MUSHIAKE ${ }^{1}$, TORU AOYAMA ${ }^{2}$, HIROKAZU SUWA ${ }^{1}$, NORIO YUKAWA ${ }^{1}$, \\ MITSUYOSHI OTA ${ }^{1}$, YASUSHI RINO ${ }^{2}$, CHIKARA KUNISAKI $^{1}$, ITARU ENDO ${ }^{3}$ and MUNETAKA MASUDA ${ }^{2}$ \\ ${ }^{1}$ Department of Surgery, Gastroenterological Center, Yokohama City University Medical Center, Yokohama, Japan; \\ ${ }^{2}$ Department of Surgery, School of Medicine, Yokohama City University, Yokohama, Japan; \\ ${ }^{3}$ Department of Gastroenterological Surgery, School of Medicine, Yokohama City University, Yokohama, Japan
}

\begin{abstract}
Background/Aim: The purpose of this study was to reveal the safety and efficacy of additional surgical resection (ASR) for high-risk T1 colorectal cancer (CRC) after endoscopic resection (ER). Patients and Methods: We retrospectively analyzed 191 patients with high-risk T1 CRC after ER. Results: The ASR was performed in 176 (92.1\%) patients and $15(7.9 \%)$ rejected ASR. All patients that underwent ASR experienced $R O$ resection; laparoscopic surgery was performed in 159 (90.3\%) patients. ClavienDindo complications $\geq$ grade II occurred in 33 patients (18.8\%). Anastomotic leakage (8.5\%) and ileus (5.7\%) were the most frequent complications. The anus function was preserved in all patients. Metastatic lymph node was detected in 21 (11.9\%) patients. There were no deaths or relapses in patients with ASR. One patient without ASR (6.7\%) had a lymph node recurrence. Conclusion: ASR was safe and effective and is recommended for high-risk T1 CRC patients after ER. A satisfactory long-term outcome can be achieved.
\end{abstract}

Colorectal cancer (CRC) is the third most common cancer worldwide and the second most frequent cause of cancerrelated deaths (1). The diagnosis of clinical T1 early stage CRC has increased by $30 \%$ worldwide because of the implementation of mass screening and patient examination $(2,3)$. Complete resection is seen as a cure of CRC, and endoscopic resection (ER) is recommended by both the

This article is freely accessible online.

Correspondence to: Hiroyuki Mushiake, Department of Surgery, Gastroenterological Center, Yokohama City University Medical Center, 4-57, Urafune-cho, Minami-ku, Yokohama, 232-0024, Japan. Tel: +81 452615656, Fax: +81 452619492, e-mail: mushiake@yokohama-cu.ac.jp

Key Words: Colorectal surgery, colorectal neoplasms, endoscopy.
National Comprehensive Cancer Network and Japanese guidelines for clinical T1 early CRC. Some patients require additional surgical resection (ASR) to achieve a radical cure because of local recurrence or the potential risk of lymph node metastasis. Lymph node metastasis has been estimated to occur in $10 \%$ of patients with high-risk T1 CRC (4-6). The 2016 Japanese Society for Cancer of the Colon and Rectum (JSCCR) guidelines for pT1 (SM) CRC recommend ASR after ER in patients with a positive vertical margin, submucosal invasion of $>1000 \mu \mathrm{m}$, lymphovascular invasion, poorly differentiated adenocarcinoma, signet-ring cell carcinoma, or mucinous carcinoma, or grade $2 / 3$ budding at the site of deepest invasion (7). ASR allows complete resection of the tumor along with potentially involved regional lymph nodes. It differs from standard CRC surgery in that resection is performed after local excision of the target tumor. Tumor cell dissemination may occur in cases with incomplete or piecemeal resection. Fibrosis of the intestinal wall is more likely to result in adhesions in the abdominal cavity after ER than after standard CRC surgery (8-10). ASR also has an increased risk of surgical morbidities like anastomotic leakage and stoma formation compared to local excision, and they may complicate patient course and recovery. On the other hand, ER is minimally invasive for diagnosis and treatment $(5,11)$. Complete local resection with negative vertical margin may lead to curative conditions. However, ER is unable to provide status of regional lymph node, and there are some high-risk cases with local recurrence and lymph node metastasis. This study aimed to evaluate the safety and effectiveness of ASR after ER for high-risk T1 CRC.

\section{Patients and Methods}

Patients. The study subjects were selected from the hospital medical records of consecutive patients with $\mathrm{CRC}$ at the Department of Surgery, Gastroenterological Center, Yokohama City University between January 2008 and December 2015. Patients with T1 CRC who were at high-risk of local recurrence and lymph node 
metastasis after ER as recommended by the JSCCR guidelines, without a preoperative diagnosis of lymph node and distant metastasis, and without synchronous or metachronous malignancies were eligible for inclusion. Patients with trans-anal tumor resection for CRC were excluded.

Ethics. The study was approved by the institutional review board and written informed consent was obtained from study patients to use data from their medical records. The study was conducted in accordance with the ethical guidelines of the Declaration of Helsinki.

Surgical procedure and follow-up. ER for T1 early CRC was performed by gastrointestinal endoscopy specialists. Laparoscopic surgery with lymphadenectomy was performed in patients at high risk of recurrence and lymph node metastasis after ER. Open surgery was performed if indicated by the patient's history. Except for lower rectal cancer, tumor localization was marked preoperatively by endoscopy using India ink tattooing and mucosal clipping. For lower rectal cancer, the optimal resection line was determined by intraoperative endoscopy. The procedures were performed by colorectal surgeons under general anesthesia within 2 months after ER. Laparoscopic surgery was performed using five trocars. Complete mesocolic excision was performed in colon cancer procedures; total mesorectal excision was performed for rectal cancer procedures. Adequate resection margins were determined following JSCCR guidelines. D2 or D3 lymphadenectomies were performed in all procedures. Functional end-to-end anastomoses were done with linear staplers in cases with a right colonic lesion, transverse colon cancer, and proximal descending colon cancer. Colonic or colorectal anastomoses were done with a circular stapler in cases with distal descending colon cancer, sigmoid colon cancer, and rectal cancer. Diverting stomas were made at the surgeons' discretion in cases with anterior rectal resection. Regular follow-up at our institution included carcinoembryonic acid (CEA) and CA19-9 assays every 3 to 6 months, computed tomography every 6 to 12 months. Colonoscopy was performed annually.

Patient characteristics, operative morbidity, and mortality. Patient characteristics including age, sex, and tumor location and pathology were retrieved from medical records. Tumor histology was described using the World Health Organization classification (12). Pathological staging was carried out by the UICC TNM classification. Tumor locations included the colon (cecum, ascending colon, transverse colon, descending colon, sigmoid colon) and rectum (rectosigmoid colon, upper rectum, lower rectum). The surgeries were organized by the type of procedure and the data included the extent of lymph node dissection, number of harvested lymph nodes, duration of surgery, volume of blood loss, postoperative stay, and complications. Postoperative complications were described with the Clavien-Dindo classification; grades II and higher were considered as major complications (13). Postoperative outcomes included the pathological findings, presence or absence of adjuvant chemotherapy after surgery, postoperative 30-day mortality, in-hospital mortality, recurrence rate, and survival rate. Adjuvant chemotherapy was offered to patients after pathological evaluation of a tumor specimen, performed within 4 weeks after surgery.
Table I. Comparison of clinicopathological characteristics before additional surgical resection.

\begin{tabular}{|c|c|c|c|}
\hline & $\begin{array}{c}\text { ASR } \\
\text { group } \\
(n=176)\end{array}$ & $\begin{array}{l}\text { Non-ASR } \\
\text { group } \\
(\mathrm{n}=15)\end{array}$ & $p$-Value \\
\hline Age (years), median (range) & $65(30-89)$ & $75(61-87)$ & $<0.01$ \\
\hline \multicolumn{4}{|l|}{ Gender, n (\%) } \\
\hline Male & $100(56.8)$ & $10(66.7)$ & \\
\hline Female & $76(43.2)$ & $5(33.3)$ & \\
\hline Tumor location, n (\%) & & & 0.044 \\
\hline Colon & $126(71.6)$ & $7(46.7)$ & \\
\hline Rectum & $50(28.4)$ & $8(53.3)$ & \\
\hline $\begin{array}{l}\text { Tumor diameter }(\mathrm{mm}) \text {, } \\
\text { median (range) }\end{array}$ & $18(6-90)$ & $38(27-110)$ & $<0.01$ \\
\hline \multicolumn{4}{|l|}{ Indication factors, $\mathrm{n}(\%)$} \\
\hline SM invasion $(\geq 1000 \mu \mathrm{m})$ & $143(81.3)$ & $7(46.7)$ & \\
\hline Lymphovascular invasion & $74(42.0)$ & $2(13.3)$ & \\
\hline Histology (Por/Sig/Muc) & $4(2.3)$ & $0(0)$ & \\
\hline Budding grade $(\geq 2 / 3)$ & $36(20.5)$ & $2(13.3)$ & \\
\hline Vertical margin positive & $55(31.3)$ & $8(53.3)$ & \\
\hline Number of indication factors, $\mathrm{n}(\%)$ & & & $<0.01$ \\
\hline Single factor & $75(42.6)$ & $12(80)$ & \\
\hline Multiple factors & $101(57.4)$ & $3(20)$ & \\
\hline
\end{tabular}

Statistical analysis. Statistical analysis included Student's $t$-test to compare the means of continuous variables with parametric distributions and the Mann-Whitney $U$-test for variables with nonparametric distributions. The chi-square test or Fisher's exact probability test were used to compare proportions. Survival was estimated by the Kaplan-Meier method and group data were compared with the log-rank test. All tests were two tailed and $p$ values $<0.05$ were considered to be significant.

\section{Results}

Demographic and clinical characteristics. A total 1821 CRC patients were treated by resective surgery at our hospital between January 2008 and December 2015. The total included 191 patients with T1 CRC treated by ER and indicated for subsequent ASR according to the JSCCR guidelines. Of those patients, 176 (92.1\%) underwent ASR and $15(7.9 \%)$ rejected ASR voluntarily and chose follow-up observation or did not receive ASR for other reasons such as comorbidities. Patient demographic and clinical characteristics are summarized in Table I. Patients that underwent ASR were younger that those without ASR $(p<0.01)$. More patients in the ASR group had colon cancer than rectal cancer and more had multiple indications for ASR than a single indication. In the group without ASR, the percentage of patients with rectal cancer was high and more patients had a single indication for ASR than multiple indications. 
Table II. Outcome of additional surgical resection.

\begin{tabular}{lc}
\hline & $\begin{array}{c}\text { ASR group } \\
(\mathrm{n}=176)\end{array}$ \\
\hline Surgical approach, $\mathrm{n}(\%)$ & \\
$\quad$ Laparoscopic surgery & $159(90.3)$ \\
Open surgery & $17(9.7)$ \\
Lymph node dissection, $\mathrm{n}(\%)$ & \\
D3 & $93(52.8)$ \\
D2 & $83(47.2)$ \\
Number of dissected lymph nodes, median (range) & $18(1-55)$ \\
Diverting stoma (Yes), $\mathrm{n}(\%)$ & $17(9.7)$ \\
Operative time (min), median (range) & $172(83-470)$ \\
Intraoperative blood loss (mg), median (range) & $10(0-1534)$ \\
Postoperative complications (CD $\geq$ grade II), $\mathrm{n}(\%)$ & $33(18.8 \%)$ \\
Anastomotic leakage & $15(8.5)$ \\
Ileus & $10(5.7)$ \\
Surgical site infection & $3(1.7)$ \\
Enteritis & $3(1.7)$ \\
Abdominal abscess & $2(1.1)$ \\
Re-operation, $\mathrm{n}(\%)$ & $5(2.8)$ \\
Postoperative stay (days), median (range) & $8(5-101)$ \\
\hline
\end{tabular}

Surgical findings and postoperative complications. The operative details and postoperative complications are summarized in Table II. Laparoscopic surgery was performed in 159 patients $(90.3 \%)$. Open surgery was performed in the remaining 17 patients $(9.7 \%)$ because of their medical histories. Two patients had severe respiratory disorders, two had chronic heart failure with severe valvular disease, and 13 patients had past histories of abdominal surgery. The procedure was switched from laparoscopic to open surgery in two patients $(1.3 \%)$ with rectal cancer and technical difficulties in establishing a satisfactory field of view including the surgical sites. The median procedure required $172 \mathrm{~min}$ (range $=83-470 \mathrm{~min}$ ) and the median blood loss was $10 \mathrm{ml}$ (range=0-1534 ml). D3 lymph node dissection was performed in 93 patients (52.8\%); D2 dissection was performed in the remaining $83(47.2 \%)$. Diverting stomas were constructed in 17 patients $(9.7 \%)$, all with rectal cancer. Grade II or higher postoperative surgical complications occurred in $18.8 \%$ of the patients. The most frequent was anastomotic leakage in 15 patients $(8.5 \%)$, followed by ileus, surgical site infection, and enteritis. Five patients with anastomotic leakage $(2.8 \%)$ required surgery for a temporary ileostomy. The diverting stomas and temporary ileostomy healed within an interval of a few months to a year. The anus was preserved in all patients. Postoperative ileus occurred in ten patients $(5.7 \%)$ and resolved within in a few days without surgical intervention. No deaths occurred. The median postoperative hospital stay was 8 days (range $=5$ - 101 days).
Table III. Pathological findings of patients with additional surgical resection.

\begin{tabular}{lc}
\hline & $\begin{array}{c}\text { ASR group } \\
(\mathrm{n}=176)\end{array}$ \\
\hline $\begin{array}{l}\text { Lymph node metastasis, } \mathrm{n}(\%) \\
\text { Positive }\end{array}$ & $21(11.9)$ \\
$\quad$ Negative & $155(88.1)$ \\
Site of metastatic lymph node, $\mathrm{n}(\%)$ & $18 / 21(85.7)$ \\
$\quad$ Paracolic & $3 / 21(14.3)$ \\
Intermediate & $0 / 21(0)$ \\
Central & $17(81.0)$ \\
Number of metastatic lymph nodes, n (\%) & $2(9.5)$ \\
1 & $1(4.8)$ \\
2 & $1(4.8)$ \\
3 & \\
4 & $155(88.1)$ \\
p-stage, n (\%) & $0(0) / 0(0)$ \\
I & $20(11.4) / 1(0.6) / 0(0)$ \\
IIA/IIB & \\
IIIA/IIIB /IIIC & $176(100)$ \\
p-curability, n (\%) & $0(0)$ \\
R1/R2 & \\
\hline
\end{tabular}

Pathological findings in ASR. The pathological findings of the ASR patients are summarized in Table III. Metastatic lymph nodes were found in 21 patients $(11.9 \%)$. Metastasis was limited to paracolic lymph nodes in $18(85.7 \%)$. The remaining three cases (14.3\%) had metastasis to intermediate lymph nodes. None of the patients had metastasis to central lymph nodes of dominant vessels. All procedures included pathological R0 resection.

Short- and long-term outcomes. The short- and long-term outcomes of both study groups are summarized in Table IV. Postoperative 30-day or in-hospital mortality were $0 \%$. Among 21 patients with metastatic lymph nodes, 19 (90.4\%) received adjuvant chemotherapy. The median follow-up was 45 (range=5-97) months. There were no cancer recurrences or cancer-related deaths of ASR patients during the followup period, but three patients died of other causes. One patient without ASR recurred to the lymph nodes 12 months after ER. That patient had three indications for ASR, submucosal invasion $\geq 1000 \mu \mathrm{m}$, lymphovascular invasion and budding grade $(\geq 2 / 3)$.

\section{Discussion}

This study investigated the safety and effectiveness of ASR for high-risk T1 CRC patients after ER. It evaluated postoperative complications and short- and long-term 
Table IV. Long-term outcomes between patients with and without additional surgical resection.

\begin{tabular}{lcc}
\hline & ASR group (n=176) & non-ASR group (n=15) \\
\hline Follow up period (month), median (range) & $45(5-97)$ & $35(22-88)$ \\
Adjuvant chemotherapy in LN positive 21 patients, $n$ (\%) & $19(90.4)$ & - \\
Recurrence, $n$ (\%) & 0 & $1(6.7)$ \\
5-year overall survival, $\%$ & 98.3 & 80.0 \\
5-year disease specific survival, $\%$ & 100 & 93.3 \\
\hline
\end{tabular}

outcomes. The primary findings confirmed lymph node metastasis in $11.9 \%$ of the high-risk T1 CRC. Over $90 \%$ of the high-risk patients received additional laparoscopic colectomy. Postoperative Clavien-Dindo grade II or greater complications occurred in 33 patients $(18.8 \%)$. The anus function was preserved in all patients; no procedure-related deaths or recurrence of disease occurred in patients that underwent ASR. The results support ASR as a radical cure in patients with high-risk T1 CRC that is effective in achieving long-term survival.

The discussion of whether ER or surgical resection is the adequate treatment for high-risk T1 CRC is ongoing. Many studies have revealed the safety, feasibility and outcome of ER for low-risk T1 CRC compared with surgical resection. On the other hand, in high-risk T1 CRC, very few reports have revealed morbidity and oncologic outcome of ASR after ER. In our study, the overall complication rate was $18.8 \%$. Anastomotic leakage and ileus were the most frequent complications, but no deaths of ASR patients occurred. The results are consistent with previous reports. Benizri et al. reported the benefit-risk balance in 64 patients with T1 CRC and ASR after ER (14). Risk was estimated by the occurrence of severe morbidity and benefit was measured by the occurrence of metastatic lymph nodes and residual tumor. Metastatic lymph nodes were diagnosed in $7.8 \%$ of the patients and residual tumors in $3.1 \%$. The overall complication rate was $25 \%$. Grade III-IV complications occurred in eight patients $(12.5 \%)$ and no deaths were observed. Logistic regression analysis found significant associations of cardiovascular comorbidities $(p=0.016)$, diabetes $(p=0.0028)$, and American Society of Anesthesiologists grade $(p=0.0004)$ and the risk of severe complications. Age was not predictive. Rickert et al. compared the surgical and oncologic outcomes of 66 highrisk T1 CRC patients with malignant polyps and ASR surgery after ER with that of 151 CRC patients with surgery without prior ER (15). Postoperative complications were observed in $31.8 \%$ of patients with or without ER $(p=1.0)$. No deaths were observed in either group. A previous review of 28 studies including $951 \mathrm{CRC}$ patients reported a surgical mortality rate of $0.8 \%$ in patients with ASR after ER (16).
Considering that the mortality of standard colorectal cancer surgery is $1 \%$ to $3 \%$ and the morbidity is $20 \%$ to $30 \%$, the results of this study confirm the safety and tolerability of ASR after ER in patients with T1 CRC compared with standard colorectal cancer surgery (14, 17-21).

ER is minimally invasive for diagnosis and treatment of T1 CRC and complete local resection with a negative vertical margin may be curative, but ER cannot determine the status of regional lymph nodes (22). About $6.3 \%$ to $13.0 \%$ of patients with high-risk T1 CRC are diagnosed with metastatic lymph nodes $(4,6,23,24)$, which is in line with the $11.9 \%$ of the patients in this study. Curative treatment is difficult to achieve in cases with a high risk of lymph node metastasis, and it is important to identify any risk factors that exist to avoid performing unnecessary ASR under the current guidelines (25-28). The decision to perform ER or surgical resection as the best treatment for high-risk T1 CRC is made by considering the balance between surgical risk and oncologic benefit. Nakadoi et al. found lymph node metastasis in 41 (8\%) of 499 patients with surgical resection for T1 CRC. Lymph node metastasis was not found in patients with submucosal invasion of less than $1800 \mu \mathrm{m}$ and no other JSCCR risk criteria (29). Oka et al. reported that ASR was not necessary even in rectal cancer with deep submucosal invasion unless other recurrence risks were present (30), and Saitoh et al. reported that the incidence of relapse after ER without ASR for T1 CRC was 3.4\% (1312 patients in five studies). Among the relapsed cases, $9 \%$ had no JSCCR risk factors for lymph node metastasis, the remaining $91 \%$ had at least one, and $54 \%$ of patients with a recurrence died of the cancer. There were more recurrences of $\mathrm{T} 1$ rectal cancer than $\mathrm{T} 1$ colon cancer in high-risk patients with lymph node metastasis (31). In this series, a high-risk patient with rectal cancer who rejected ASR relapsed within one year. Relapse has a poor prognosis and is not a rare occurrence in high-risk patients (32). Therefore, the study results support the oncologic benefit of ASR for patients with high-risk T1 colon cancer and even for patients with T1 rectal cancer.

The study limitations include selection bias resulting from an ASR group that was younger than the non-ASR 
group. However, as the study population reflects actual clinical practice, the results are useful. The moderate sample size, retrospective design, and single center setting may limit generalizing the results, but no large prospective randomized studies are available. Ethical implications may limit the possibility a prospective randomized evaluation of ASR after ER.

In conclusion, ASR for high-risk T1 colorectal cancer after ER was safe and effective. ASR is recommended for patients at high-risk of local recurrence and lymph node metastasis following the JSCCR guidelines. A satisfactory long-term outcome can be achieved.

\section{Conflicts of Interest}

The Authors declare no conflicts of interest regarding this study.

\section{Authors' Contributions}

All Authors contributed equally to this study. Details of contributions by each author are as follows; Concept and study design were conducted by K. Iguchi, H. Mushiake, T. Aoyama, C. Kunisaki and H. Suwa. Data collection and literature search were done by K. Iguchi. Data analysis and interpretation were done by K. Iguchi, N. Yukawa, M Ota, I. Endo, Y. Rino and M. Masuda. Interpretation of data was done by all 10 investigators. Drafting the article was done by K. Iguchi and T. Aoyama and H. Mushiake. Finally, this article was revised and approved by all 10 investigators.

\section{Acknowledgements}

The Authors would like to give heartfelt thanks to Dr. Kingo Hirasawa, and all digestive endoscopists at the Gastroenterological Center of Yokohama City University Medical Center who always gave the best treatment and provided carefully considered feedback and valuable comments.

\section{References}

1 Todua F, Gagua R, Maglakelidze M and Maglakelidze D: Cancer incidence and mortality - Major patterns in GLOBOCAN 2012, worldwide and Georgia. Bull Georg Natl Acad Sci 9(1): 168$173,2015$.

2 Stamos MJ and Murrell Z: Management of early rectal T1 and T2 cancers. Clinical Cancer Res 13(22 Pt 2): 6885s-6889s, 2007. PMID: 18006794. DOI: 10.1158/1078-0432.CCR-07-1150

3 Iida S, Hasegawa H, Okabayashi K, Moritani K, Mukai M and Kitagawa Y: Risk factors for postoperative recurrence in patients with pathologically t1 colorectal cancer. World J Surg 36(2): 424430, 2012. PMID: 22187130. DOI: 10.1007/s00268-011-1378-y

4 Muto T and Oya M: Recent advances in diagnosis and treatment of colorectal T1 carcinoma. Dis Colon Rectum 46(10): S89-93, 2003. PMID: 14530664. DOI: 10.1097/01.DCR.000008 3525.97708.B5

5 Tanaka S, Haruma K, Oh-E H, Nagata S, Hirota Y, Furudoi A, Amioka T, Kitadai Y, Yoshihara $\mathrm{M}$ and Shimamoto $\mathrm{F}$ : Conditions of curability after endoscopic resection for colorectal carcinoma with submucosally massive invasion. Oncol Rep 7(4): 783-788, 2000. PMID: 10854544.

6 Nascimbeni R, Burgart LJ, Nivatvongs S and Larson DR: Risk of lymph node metastasis in $\mathrm{T} 1$ carcinoma of the colon and rectum. Dis Colon Rectum 45(2): 200-206, 2002. PMID: 11852333. DOI: $10.1007 / \mathrm{s} 10350-004-6147-7$

7 Watanabe T, Muro K, Ajioka Y, Hashiguchi Y, Ito Y, Saito Y, Hamaguchi T, Ishida H, Ishiguro M, Ishihara S, Kanemitsu Y, Kawano H, Kinugasa Y, Kokudo N, Murofushi K, Nakajima T, Oka S, Sakai Y, Tsuji A, Uehara K, Ueno H, Yamazaki K, Yoshida M, Yoshino T, Boku N, Fujimori T, Itabashi M, Koinuma N, Morita T, Nishimura G, Sakata Y, Shimada Y, Takahashi K, Tanaka S, Tsuruta O, Yamaguchi T, Yamaguchi N, Tanaka T, Kotake K and Sugihara K: Japanese Society for Cancer of the Colon and Rectum (JSCCR) guidelines 2016 for the treatment of colorectal cancer. Int J Clin Oncol 23(1): 1-34, 2018. PMID: 28349281. DOI: 10.1007/s10147-017-1101-6

8 Ma MX and Bourke MJ: Complications of endoscopic polypectomy, endoscopic mucosal resection and endoscopic submucosal dissection in the colon. Best Pract Res Clin Gastroenterol 30(5): 749-767, 2016. PMID: 27931634. DOI: 10.1016/j.bpg.2016.09.009

9 Sethi A and Wong Kee Song LM: Adverse events related to colonic endoscopic mucosal resection and polypectomy. Gastrointest Endosc Clin N Am 25(1): 56-69, 2015. PMID: 25442958. DOI: 10.1016/j.giec.2014.09.007

10 Koch M, Kienle P, Sauer P, Willeke F, Buhl K, Benner A, Lehnert T, Herfarth C, Von Knebel Doeberitz M and Weitz J: Hematogenous tumor cell dissemination during colonoscopy for colorectal cancer. Surg Endosc Other Interv Tech 18(4): 587591, 2004. PMID: 14735340. DOI: 10.1007/s00464-003-9066-0

11 Tomiki Y, Kawai M, Kawano S, Ishiyama S, Sugimoto K, Takahashi M, Kojima Y, Murakami T, Ritsuno H, Shibuya T, Sakamoto $\mathrm{N}$ and Sakamoto K: Endoscopic submucosal dissection decreases additional colorectal resection for $\mathrm{T} 1$ colorectal cancer. Med Sci Monit 24: 6910-6917, 2018. PMID: 30267631. DOI: $10.12659 / \mathrm{msm} .909380$

12 Bosman FT, Carneiro F, Hruban RH and Theise ND: WHO Classification of Tumours of the Digestive System, Fourth Edition. In: International Agency for Research on Cancer. International Agency for Research on Cancer, pp. 417, 2010.

13 Dindo D, Demartines N and Clavien P-A: Classification of Surgical Complications. Ann Surg 240(2): 205-213, 2004. PMID: 15273542. DOI: 10.1097/01.sla.0000133083.54934.ae

14 Benizri EI, Bereder JM, Rahili A, Bernard JL, Vanbiervliet G, Filippi J, Hebuterne X and Benchimol D: Additional colectomy after colonoscopic polypectomy for $\mathrm{T} 1$ colon cancer: A fine balance between oncologic benefit and operative risk. Int $\mathrm{J}$ Colorectal Dis 27(11): 1473-1478, 2012. PMID: 22454048. DOI: 10.1007/s00384-012-1464-0

15 Rickert A, Aliyev R, Belle S, Post S, Kienle P and Kähler G: Oncologic colorectal resection after endoscopic treatment of malignant polyps: Does endoscopy have an adverse effect on oncologic and surgical outcomes? Gastrointest Endosc 79(6): 951960, 2014. PMID: 24412574. DOI: 10.1016/j.gie.2013. 11.014

16 Hassan C, Zullo A, Risio M, Rossini FP and Morini S: Histologic risk factors and clinical outcome in colorectal malignant polyp: A pooled-data analysis. Dis Colon Rectum 48(8): 1588-1596, 2005. PMID: 15937622. DOI: $10.1007 /$ s10350-005-0063-3 
17 Yamamoto S, Inomata M, Katayama H, Mizusawa J, Etoh T, Konishi F, Sugihara K, Watanabe M, Moriya Y and Kitano S: Short-term surgical outcomes from a randomized controlled trial to evaluate laparoscopic and open D3 dissection for stage II/III colon cancer: Japan clinical oncology group study JCOG 0404. Ann Surg 260(1): 23-30, 2014. PMID: 24509190. DOI: 10.1097/ SLA.0000000000000499

18 Bokey EL, Chapuis PH, Fung C, Hughes WJ, Koorey SG, Brewer D, Newland RC and Chiu YSY: Postoperative morbidity and mortality following resection of the colon and rectum for cancer. Dis Colon Rectum 38(5): 480-487, 1995. PMID: 7736878. DOI: $10.1007 / \mathrm{BF} 02148847$

19 Clinical Outcomes of Surgical Therapy Study Group, Nelson H, Sargent DJ, Wieand HS, Fleshman J, Anvari M, Stryker SJ, Beart RW, Hellinger M, Flanagan R, Peters W and Ota D: A comparison of laparoscopically assisted and open colectomy for colon cancer. N Engl J Med 350(20): 2050-2059, 2004. PMID: 15141043. DOI: 10.1056/NEJMoa032651

20 Whitlow C, Gathright JB, Hebert SJ, Beck DE, Opelka FG, Timmcke AE and Hicks TC: Long-term survival after treatment of malignant colonic polyps. Dis Colon Rectum 40(8): 929-934, 1997. PMID: 9269809. DOI: 10.1007/BF02051200

21 Antoniou SA, Antoniou GA, Koch OO, Pointner R and Granderath FA: Laparoscopic colorectal surgery confers lower mortality in the elderly: a systematic review and meta-analysis of 66,483 patients. Surg Endosc Other Interv Tech 29(2): 322333, 2015. PMID: 24986017. DOI: 10.1007/s00464-014-3672-x

22 Tanaka S, Terasaki M, Kanao H, Oka S and Chayama K: Current status and future perspectives of endoscopic submucosal dissection for colorectal tumors. Dig Endosc 24: 73-79, 2012. PMID: 22533757. DOI: 10.1111/j.1443-1661.2012.01252.x

23 Yamamoto S, Watanabe M, Hasegawa H, Baba H, Yoshinare K, Shiraishi J and Kitajima M: The risk of lymph node metastasis in T1 colorectal carcinoma. Hepatogastroenterology 51(58): 9981000, 2004. PMID: 15239233.

24 Tanaka S, Haruma K, Teixeira CR, Tatsuta S, Ohtsu N, Hiraga Y, Yoshihara M, Sumii K, Kajiyama G and Shimamoto F: Endoscopic treatment of submucosal invasive colorectal carcinoma with special reference to risk factors for lymph node metastasis. J Gastroenterol 30(6): 710-717, 1995. PMID: 8963387. DOI: $10.1007 / \mathrm{BF} 02349636$

25 Kobayashi H, Higuchi T, Uetake H, Iida S, Ishikawa T, Ishiguro $\mathrm{M}$ and Sugihara K: Resection with en bloc removal of regional lymph node after endoscopic resection for $\mathrm{T} 1$ colorectal cancer. Ann Surg Oncol 19(13): 4161-4167, 2012. PMID: 22772868. DOI: $10.1245 / \mathrm{s} 10434-012-2471-7$

26 Takatsu Y, Fukunaga Y, Hamasaki S, Ogura A, Nagata J, Nagasaki T, Akiyoshi T, Konishi T, Fujimoto Y, Nagayama S and Ueno M: Recurrent colorectal cancer after endoscopic resection when additional surgery was recommended. World J Gastroenterol 22(7): 2336-2341, 2016. PMID: 26900295. DOI: 10.3748/wjg.v22.i7.2336
27 Kobayashi H, Mochizuki H, Morita T, Kotake K, Teramoto T, Kameoka S, Saito Y, Takahashi K, Hase K, Oya M, Maeda K, Hirai T, Kameyama M, Shirouzu K and Sugihara K: Characteristics of recurrence after curative resection for $\mathrm{T} 1$ colorectal cancer: Japanese multicenter study. J Gastroenterol 46(2): 203-211, 2011. PMID: 21152938. DOI: 10.1007/s00535-010-0341-2

28 Kouyama Y, Kudo S ei, Miyachi H, Ichimasa K, Matsudaira S, Misawa M, Mori Y, Kudo T, Hayashi T, Wakamura K, Ishida F and Hamatani S: Risk factors of recurrence in T1 colorectal cancers treated by endoscopic resection alone or surgical resection with lymph node dissection. Int J Colorectal Dis 33(8): 1029-1038, 2018. PMID: 29748707. DOI: 10.1007/s00384-0183081-z

29 Nakadoi K, Tanaka S, Kanao H, Terasaki M, Takata S, Oka S, Yoshida S, Arihiro K and Chayama K: Management of T1 colorectal carcinoma with special reference to criteria for curative endoscopic resection. J Gastroenterol Hepatol 27(6): 1057-1062, 2012. PMID: 22142484. DOI: 10.1111/j.14401746.2011.07041.x

30 Oka S, Tanaka S, Nakadoi K, Kanao H and Chayama K: Risk analysis of submucosal invasive rectal carcinomas for lymph node metastasis to expand indication criteria for endoscopic resection. Dig Endosc 25: 21-25, 2013. PMID: 23617644. DOI: 10.1111/den.12089

31 Saitoh Y, Inaba Y, Sasaki T, Sugiyama R, Sukegawa R and Fujiya M: Management of colorectal T1 carcinoma treated by endoscopic resection. Dig Endosc 28(3): 324-329, 2016. PMID: 26076802. DOI: $10.1111 /$ den.12503

32 Backes Y, De Vos Tot Nederveen Cappel WH, Van Bergeijk J, Ter Borg F, Schwartz MP, Spanier BWM, Geesing JMJ, Kessels K, Kerkhof M, Groen JN, Wolfhagen FHJ, Seerden TCJ, Van Lelyveld N, Offerhaus GJA, Siersema PD, Lacle MM and Moons LMG: Risk for incomplete resection after macroscopic radical endoscopic resection of $\mathrm{T} 1$ colorectal cancer: A Multicenter Cohort Study. Am J Gastroenterol 112(5): 785-796, 2017. PMID: 28323275. DOI: 10.1038/ajg.2017.58 